\title{
High-mobility group box 1 accelerates lipopolysaccharide-induced lung fibroblast proliferation in vitro: involvement of the NF- $K B$ signaling pathway
}

\author{
Wen Li ${ }^{1,3}$, Qiaoyi Xu ${ }^{1,3}$, Yuxiao Deng ${ }^{1}$, Zhongwei Yang ${ }^{2}$, Shunpeng Xing ${ }^{1}$, Xianyuan Zhao ${ }^{1}$, Ping Zhu ${ }^{1}$, Xiangrui Wang ${ }^{2}$, \\ Zhengyu $\mathrm{He}^{1}$ and Yuan Gao ${ }^{1}$
}

The mechanism underlying lipopolysaccharide (LPS)-induced aberrant proliferation of lung fibroblasts in Gram-negative bacilli-associated pulmonary fibrosis is unknown. High-mobility group box 1 (HMGB1) is a ubiquitous nuclear protein that is released from the nuclei of lung fibroblasts after LPS stimulation. It can exasperate LPS-induced inflammation and hasten cell proliferation. Thus, this study investigated the effects of LPS- and/or HMGB1-stimulating murine lung fibroblasts on gene expression using various assays in vitro. Thiazolyl-diphenyl-tetrazolium bromide (MTT) assay data showed that either LPS or HMGB1 could induce lung fibroblast proliferation. Endogenous HMGB1 secreted from lung fibroblasts was detected by enzyme-linked immunosorbent assay (ELISA) $48 \mathrm{~h}$ after LPS stimulation. Pretreatment with an anti-HMGB1 antibody inhibited the proliferative effects of LPS on lung fibroblasts. DNA microarray data showed that the NF- $K B$ signaling genes were upregulated in cells after stimulated with LPS, HMGB1, or both. Secretion of matrix metalloproteinase (MMP)-2 and MMP-9, and tissue inhibitor of metalloproteinase 2 (TIMP-2) was significantly upregulated after treatment with LPS, HMGB1, or their combination. However, an NF-KB inhibitor was able to downregulate levels of these proteins. In addition, levels of Toll-like receptor 4 (TLR4), Toll-like receptor 2 (TLR2), and receptors for advanced glycation end products (RAGE) mRNA and proteins were also upregulated in these cells after LPS treatment and further upregulated by LPS plus HMGB1. In conclusion, the data from the current study demonstrate that LPS-induced lung fibroblast secretion of endogenous HMGB1 can augment the proproliferative effects of LPS and, therefore, may play a key role in exacerbation of pulmonary fibrosis. The underlying molecular mechanisms are related to the activation of the TLR4/NF-KB signaling pathway and its downstream targets.

Laboratory Investigation (2015) 95, 635-647; doi:10.1038/labinvest.2015.44; published online 13 April 2015

Pulmonary fibrosis is characterized by abnormal activation and proliferation of lung fibroblasts. ${ }^{1}$ Lipopolysaccharide (LPS), a prominent component of endotoxins from Gramnegative bacilli, is an important etiologic factor of organ fibrosis. ${ }^{2}$ Our previous study showed that LPS stimulated lung fibroblasts to undergo aberrant proliferation and secretion of collagen, the effects that exacerbate pulmonary fibrosis. ${ }^{3-6}$ Aberrant proliferation of lung fibroblasts plays an important role in LPS-induced fibrogenesis during early-stage pulmonary fibrosis. However, the molecular mechanism underlying this induction of fibrogenesis is not well understood.

High-mobility group box 1 (HMGB1) is a ubiquitous nuclear protein ${ }^{7-12}$ that acts as a crucial factor in acute lung injury progression ${ }^{13,14}$ and pulmonary fibrosis. ${ }^{15} \mathrm{HMGB} 1$ can be released actively or passively from various cells in response to stimulation of LPS or endogenous proinflammatory cytokines. ${ }^{16-19}$ HMGB1 can induce proliferation and migration of human gingival fibroblasts in vitro. ${ }^{18}$ Endogenous HMGB1 has been shown to augment the LPS-induced inflammatory responses in peritoneal macrophages ${ }^{7}$ and synovial fibroblasts, ${ }^{8}$ and to enhance LPS-induced proliferation of human gingival fibroblasts. ${ }^{20}$ HMGB1 involvement in fibroblast proliferation suggests that it may contribute to pulmonary fibrosis. However, the mechanism by which LPS promotes proliferation of lung fibroblasts is unclear. That is, it is not known whether LPS promotes lung fibroblast

${ }^{1}$ Department of Critical Care Medicine, Ren Ji Hospital, School of Medicine, Shanghai Jiao Tong University, Shanghai, China and ${ }^{2}$ Department of Anesthesiology, Ren Ji Hospital, School of Medicine, Shanghai Jiao Tong University, Shanghai, China

Correspondence: Dr Z He, MD, PhD, or Dr Y Gao, MD, PhD, Department of Critical Care Medicine, Ren Ji Hospital, School of Medicine, Shanghai Jiao Tong University, 1630 Dong Fang Road, Shanghai 200127, China.

E-mail: zhengyuheshsmu@163.com or gaoyuanshsmu@163.com

${ }^{3}$ These two authors contributed equally to this work.

Received 16 May 2014; revised 23 February 2015; accepted 24 February 2015 
proliferation only indirectly through LPS-induced secretion of HMGB1, which then promotes the proliferation, or whether LPS has an additional effect on proliferation, as has been observed in other types of fibroblasts in vitro. ${ }^{20}$

Thus, in this study, we first compared lung fibroblast proliferation in culture following stimulation with LPS alone, HMGB1 alone, or the two in combination to probe the role of HMGB1 in this process. We then assessed the effects of the endogenous HMGB1 secretion from lung fibroblasts after LPS stimulation on cell proliferation. In parallel, we administered an anti-HMGB1 antibody to block HMGB1 activity during LPS-induced lung fibroblast proliferation. We then performed a cDNA microarray analysis to identify which genes were differentially expressed genes across the three treatment conditions. Finally, we compared the expression of NF- $\kappa \mathrm{B}$ pathway genes (eg, matrix metalloproteinase (MMP)-2 and -9 , tissue inhibitor of metalloproteinase 2 (TIMP-2), and the LPS- and HMGB1-related receptors Toll-like receptor 4 (TLR4), Toll-like receptor 2 (TLR2), and receptors for advanced glycation end products (RAGE)) in LPS- $v s$ HMGB1-induced cell proliferation.

\section{MATERIALS AND METHODS}

\section{Cell Lines and Culture}

Mouse lung fibroblasts (MIC-CELL-0040) were obtained from Wuhan Pricells Biotechnology \& Medicine (Wuhan, China) and cultured in Dulbecco's modified Eagle's medium (DMEM) supplemented with 10\% fetal calf serum (FCS), $2 \mathrm{mM}$ L-glutamine, $100 \mathrm{IU} / \mathrm{ml}$ penicillin $\mathrm{G}$, and $100 \mathrm{IU} / \mathrm{ml}$ streptomycin at $37^{\circ} \mathrm{C}$ in a humidified $5 \% \mathrm{CO}_{2}$ incubator (all from Invitrogen/Labotect, Gottingen, Germany). The growth medium was refreshed every 3 days. When the culture reached $80 \%$ confluence, adherent cells were detached by exposure to $0.25 \%$ trypsin for $5 \mathrm{~min}$, and cells were seeded into six-well plates at 1:5-10 dilutions, depending on the requirements of the particular experiment.

\section{Cell Treatment}

Cells were seeded into each of treatment groups and treated with LPS (10, 50, or $100 \mathrm{ng} / \mathrm{ml})$, HMGB1 $(0.01,0.1$, or $1.0 \mu \mathrm{g} /$ $\mathrm{ml})$, or both $(10 \mathrm{ng} / \mathrm{ml} \mathrm{LPS}+0.01 \mu \mathrm{g} / \mathrm{ml}$ HMGB1, $50 \mathrm{ng} / \mathrm{ml}$ LPS $+0.1 \mu \mathrm{g} / \mathrm{ml}$ HMGB1, or $100 \mathrm{ng} / \mathrm{ml}$ LPS $+1 \mu \mathrm{g} / \mathrm{ml}$ HMGB1) for $0,12,24$, and $48 \mathrm{~h}$. Some cultures were pretreated with the NF- $\kappa \mathrm{B}$ inhibitor pyrrolidine dithiocarbamate (PDTC, $30 \mu \mathrm{M}$, Sigma-Aldrich, St Louis, MO, USA). LPS (O55:B5 Escherichia coli) and recombinant human HMGB1 (rhHMGB1) were purchased from Sigma-Aldrich. All dilutions were prepared in $0.25 \mathrm{ml}$ of sterile phosphate-buffered saline (PBS). PBS was used as a negative control. Recombinant human RAGE Fc chimera (RAGE-Fc) was purchased from R\&D Systems (Minneapolis, MN, USA). A chicken anti-mouse IgY (Abcam, UK) was used as a negative control for all antibody experiments. Normal Ig was used as a reference in place of HMGB1 antibody in the control group and LPS group. Following a 1-h pretreatment with $4 \mu \mathrm{g} / \mathrm{ml}$ of an anti-
HMGB1, anti-TLR2, or anti-TLR4 neutralizing antibody (all from Shino-Test, Tokyo, Japan), cells were stimulated with LPS $(100 \mathrm{ng} / \mathrm{ml})$ or exposed to PBS for $48 \mathrm{~h}$.

\section{Methyl Thiazolyl-Diphenyl-Tetrazolium Bromide (MTT) Cell Viability Assay}

MTT assays were used to detect lung fibroblast viability. Cells were grown and prepared at a concentration of $3.5 \times 10^{4} / 1$, and $100-\mu \mathrm{l}$ aliquots of cells were plated in a 96-well plates containing 10\% FCS-DMEM and allowed to incubate overnight in accordance with the specified group treatment. After 36-h treatments, the medium was changed to fresh DMEM (100 $\mu \mathrm{l}$ per well). Then, $10 \mu \mathrm{l}$ of MTT solution $(5 \mathrm{mg} /$ $\mathrm{ml}$ in PBS) was added to each well, and the cells were incubated for an additional $4 \mathrm{~h}$ at $37^{\circ} \mathrm{C}$ in $5 \% \mathrm{CO}_{2}$. The colored formazan product was then dissolved in $100 \mu \mathrm{l}$ of dimethyl sulfoxide (DMSO), and the optical density (OD) of each well was read at $490 \mathrm{~nm}$.

\section{Enzyme-Linked Immunosorbent Assay (ELISA)}

Secretion of HMGB1, MMP-2, MMP-9, and TIMP-2 proteins was detected by ELISA. After a 48-h LPS stimulation (or sham control), supernatant fractions of cell culture were collected. HMGB1 concentration was detected with commercially available ELISA kits (HMGB1, Shino-Test Corporation;
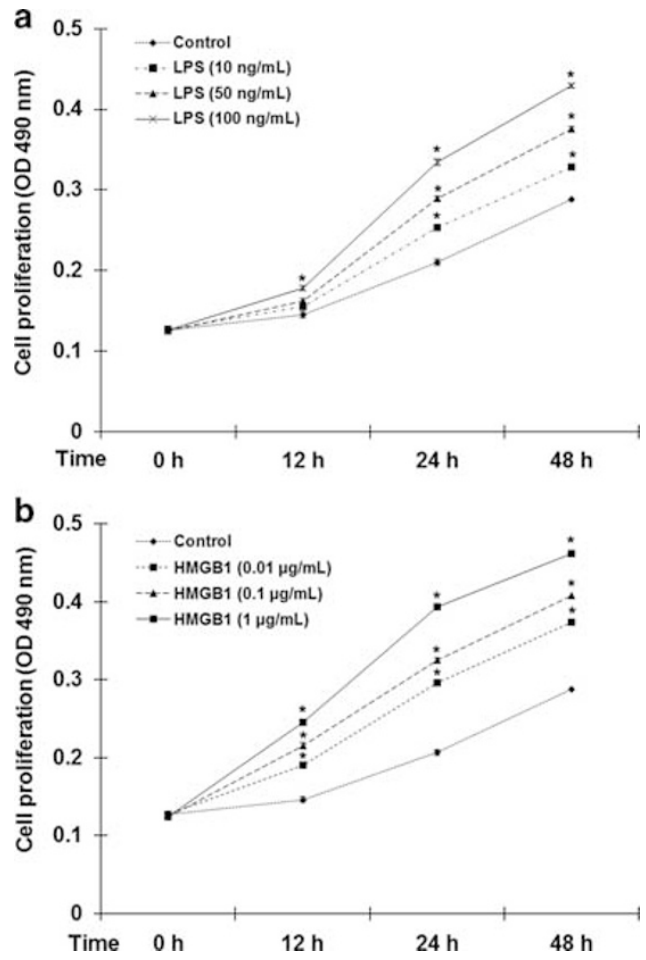

Figure 1 LPS and HMGB1 induce lung fibroblast proliferation. Increased cell proliferation compared with PBS-exposed control cells, as determined by MTT assay $\left(\mathrm{OD}_{490 \mathrm{~nm}}\right)$, following LPS (a) or HMGB1 (b) exposure for 12, 24 , and $48 \mathrm{~h}$. Mean values from triplicate experiments are shown with s.d. ${ }^{*} P<0.001$ vs control cells at the same time point. 

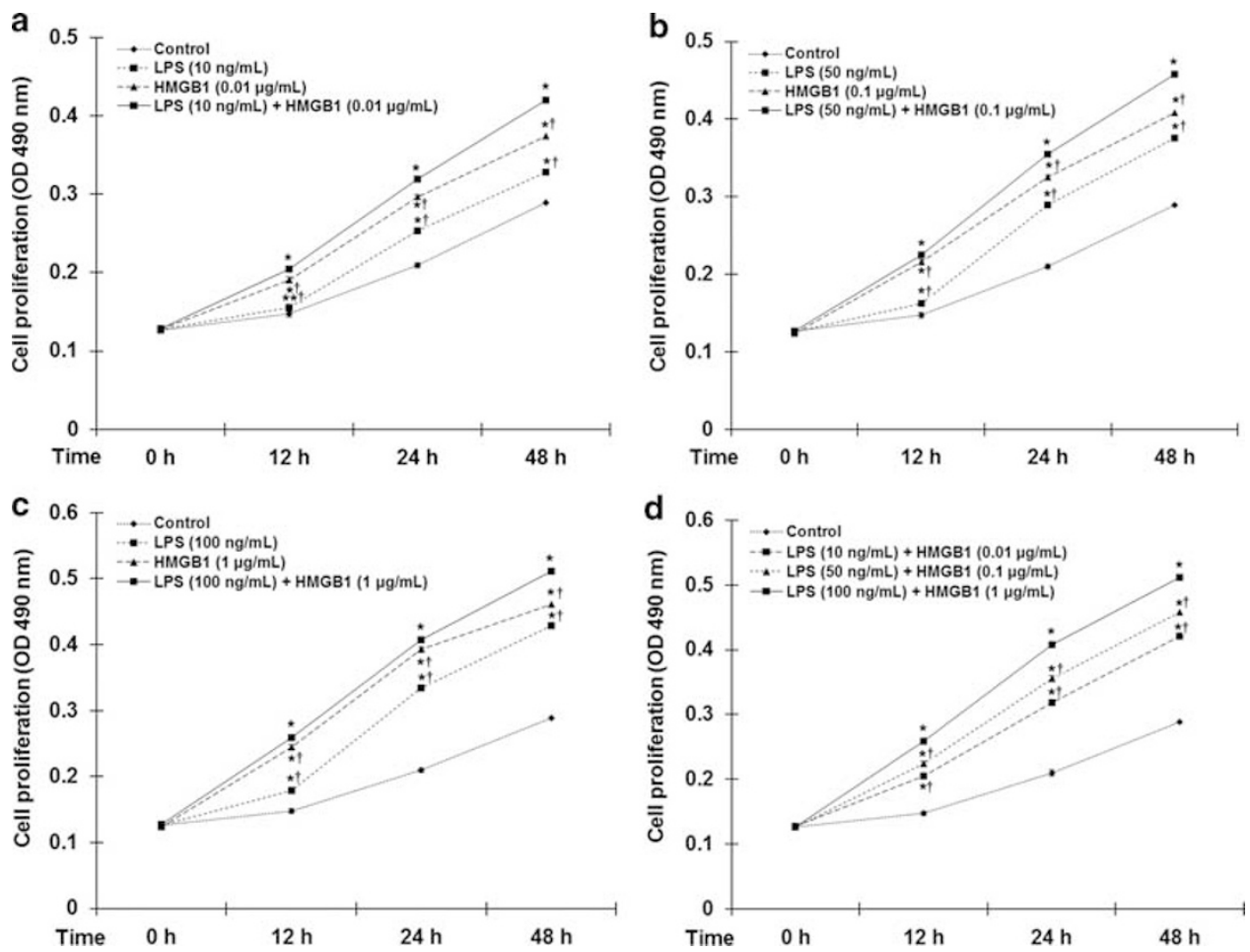

Figure 2 HMGB1 enhances LPS-induced proliferative effect in lung fibroblasts. MTT assay data $\left(\mathrm{OD}_{490 \mathrm{~nm}}\right)$ showing the proproliferative effects of 12,24 , and 48-h exposure of lung fibroblasts to low (a), medium (b), and high (c) doses of LPS alone, HMGB1 alone, or both, compared with control cells exposed to only PBS. (d) Dose-dependent additive effects of HMGB1 and LPS on proliferation. ${ }^{*} P<0.001,{ }^{* *} P<0.01$ vs control cells (a-d); ${ }^{\dagger} P<0.001$ vs LPS+HMGB1-stimulated cells at the same time point $(\mathbf{a}-\mathbf{c}) ;{ }^{\dagger} P<0.001 \mathrm{vs}$ LPS $(100 \mathrm{ng} / \mathrm{ml})+$ HMGB1 $(1 \mu \mathrm{g} / \mathrm{ml})$-stimulated cells at the same time point $(\mathbf{d})$. Mean values of triplicate experiments are shown with s.d. error bars.

MMP-2 and MMP-9, R\&D Systems) according to the manufacturers' instructions as described previously. ${ }^{21}$ For detection of TIMP-2, a mouse anti-TIMP-2 antibody (Abcam, Cambridge, MA, USA) was used as the primary antibody and all other steps were performed in accordance with standard ELISA methods.

\section{cDNA Microarray Analysis}

Lung fibroblasts were stimulated for $24 \mathrm{~h}$ with LPS (100 ng/ $\mathrm{ml})$, HMGB1 $(1 \mu \mathrm{g} / \mathrm{ml})$, or both $(100 \mathrm{ng} / \mathrm{ml}$ LPS plus $1 \mu \mathrm{g} / \mathrm{ml}$ HMGB1), and PBS-treated cells served as a nonstimulated control. Total cellular RNA was isolated from cells using the Trizol reagent (Invitrogen) and purified with a total RNA prep kit (Illumina, San Diego, CA, USA). RNA quality was checked using a Bioanalyzer 2200 (Agilent, Santa Clara, CA, USA) and stored at $-80^{\circ} \mathrm{C}$ until use. The RNA samples with an RNA integrity number $>7.0$ were used for cDNA microarray analysis. In brief, cDNA was prepared using One-Cycle Target Labeling and Control Reagents (Illumina) and cRNA was then created with a GeneChip IVT labeling kit (Illumina) and these biotin-labeled, fragmented (B200 nt) cRNA probes were hybridized to GEX-HBY arrays for $16 \mathrm{~h}$ at $45^{\circ} \mathrm{C}$ (mouse WG-6 expression BeadChips; Illumina). All arrays were washed, stained, and read by an Illumina BeadChip Reader. The fluorescence signal was excited at

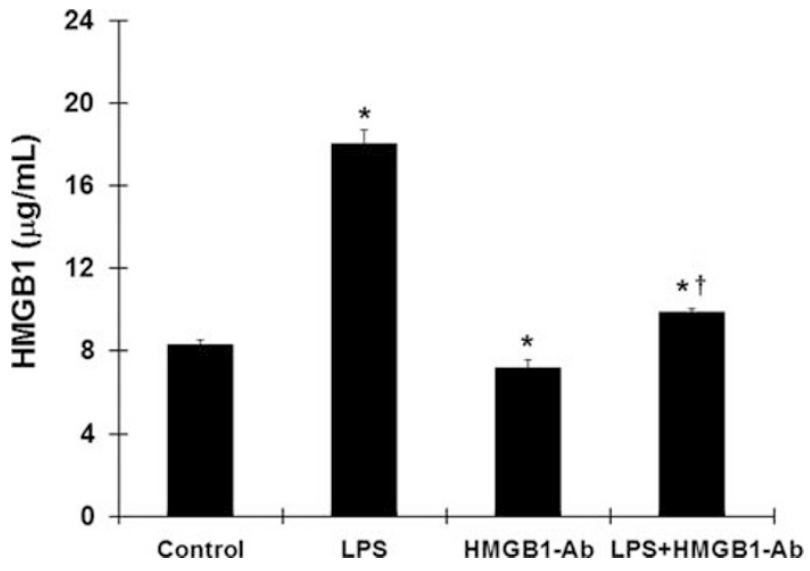

Figure 3 LPS induces HMGB1 secretion in lung fibroblasts. ELISAs of supernatant samples from cells exposed to LPS (final concentration of $100 \mathrm{ng} / \mathrm{ml}$ ) or sham, stimulation for $48 \mathrm{~h}$ following a 1 - $\mathrm{h}$ pretreatment with anti-HMGB1 antibody $(4 \mu \mathrm{g} / \mathrm{ml})$ or lgY-negative control antibody (control and LPS groups). Mean values from triplicate experiments are shown with s.d. error bars. ${ }^{*} P<0.001$ vs sham-stimulated controls. ${ }^{\dagger} P<0.001$ vs LPS alone group.

$570 \mathrm{~nm}$, and data were collected via a confocal scanner. Data were analyzed using Illumina BeadStudio data analysis software. Three replicates of each sample were pooled together. Differentially expressed genes were identified based 
a

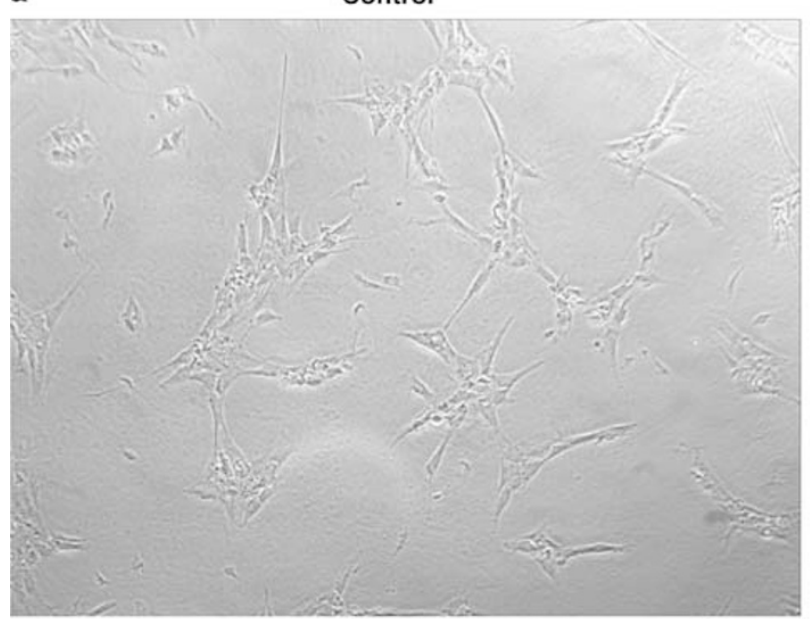

C

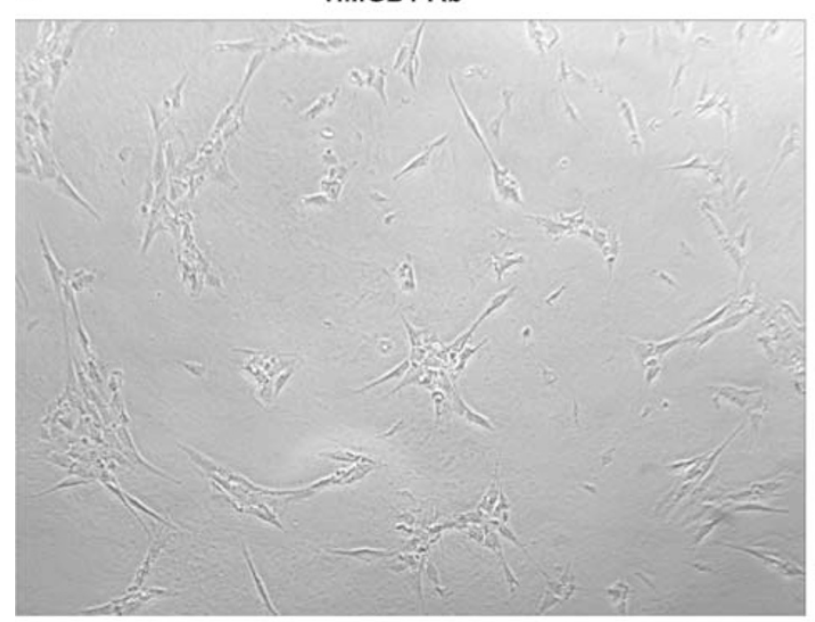

b

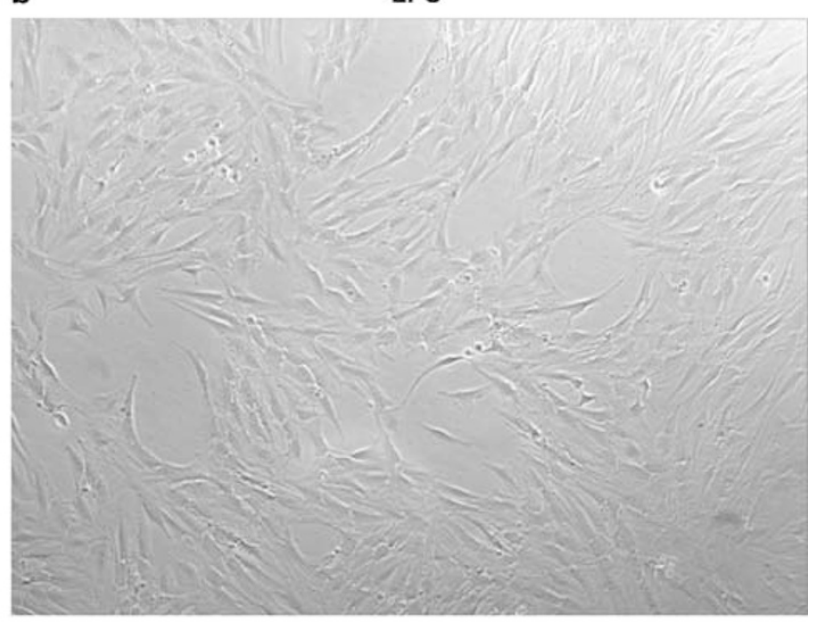

d

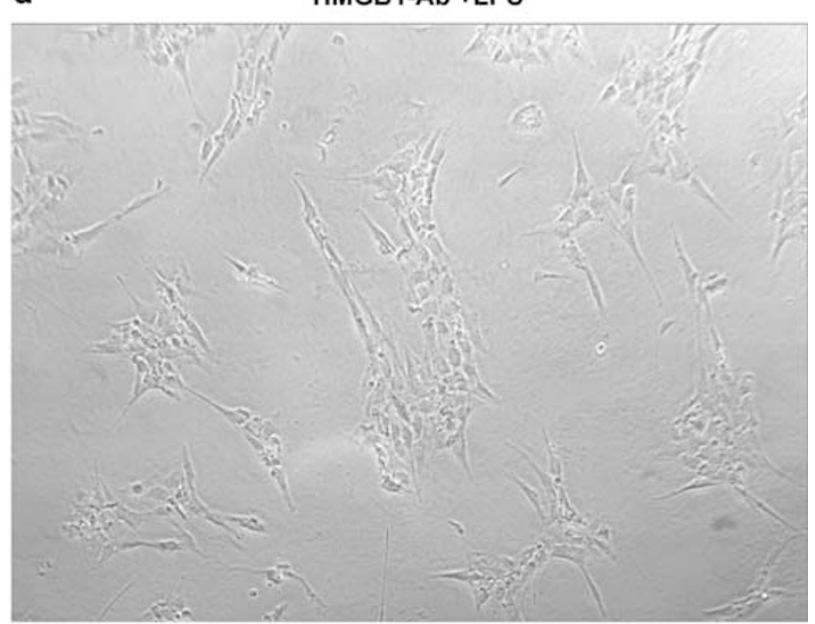

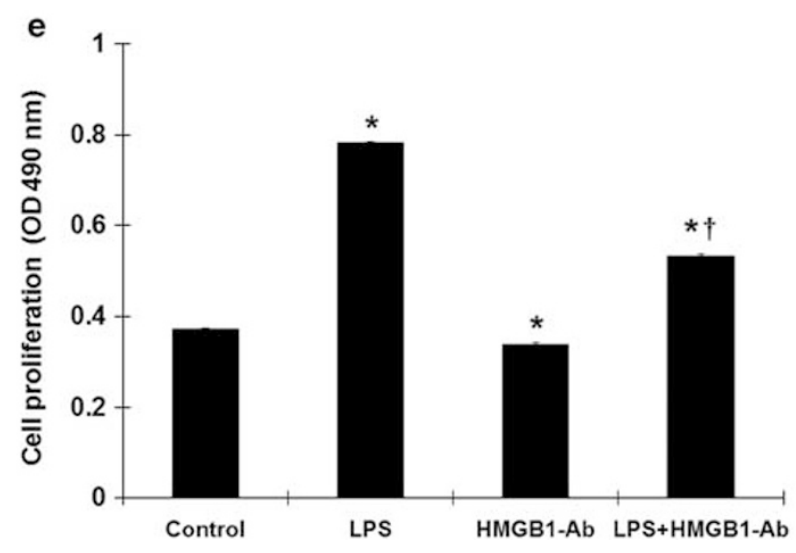

Figure 4 HMGB1 neutralization inhibits LPS-induced lung fibroblast proliferation. (a-d) Images of cultured cells following stimulation with or without LPS (final concentration, $100 \mathrm{ng} / \mathrm{ml}$ ) for $48 \mathrm{~h}$ following 1-h pretreatment with anti-HMGB1 antibody $(4 \mu \mathrm{g} / \mathrm{ml}$ ) or lgY-negative control antibody (control and LPS groups) $(\times 100)$. (e) MTT assay $\left(\mathrm{OD}_{490 \mathrm{~nm}}\right)$ proliferation data of cells following the aforementioned treatments. Mean values from triplicate experiments are shown with s.d. error bars. ${ }^{*} P<0.001$ vs control cells; ${ }^{\dagger} P<0.001$ vs LPS alone.

on a random variance model (RVM) $t$-test and false discovery rate (FDR) analysis, as described previously. ${ }^{5}$

After the statistical and FDR analyses, we selected differentially expressed genes using the criterion of a fold change $>2$ and a FDR threshold of $<0.05$. Expression of some of these genes was validated by qRT-PCR, and a high correlation was observed between our qPCR and microarray data. The main functions of genes were determined by GO 
Table 1 Numbers of differentially expressed genes following specified treatments in lung fibroblasts

\begin{tabular}{lccccc}
\hline Effect & LPS vs Con. & HMGB1 vs Con. & LPS+ HMGB1 vs Con. & LPS+ HMGB1 vs LPS & LPS+ HMGB1 vs HMGB1 \\
\hline Upregulated, no. of genes & 2231 & 1707 & 860 & 621 & 1484 \\
Downregulated, no. of genes & 764 & 580 & 740 & 1826 \\
\hline
\end{tabular}

Con, control; HMGB1, high-mobility group box 1 protein; LPS, lipopolysaccharide.

analysis as described previously. ${ }^{22-24}$ We used Fisher's exact test and $\chi^{2}$ test results to classify the GO categories, and FDRs were calculated to correct $P$-values. Pathway analysis was used to identify the significantly changed pathways of the differential genes according to KEGG, Biocarta, and Reatome..$^{25-27}$

\section{Protein Extraction and Western Blot}

Protein expression was assessed with western blots. Briefly, cells were collected and lysed with an RIPA lysis buffer on ice for 10-15 min. Supernatants were collected after centrifugation and protein concentration was quantified using the bicinchoninic acid method. The protein samples were then resolved by sodium dodecyl sulfate-polyacrylamide gel electrophoresis (SDS-PAGE) and transferred onto polyvinylfluoride membranes. The membranes were incubated for $16 \mathrm{~h}$ at $4{ }^{\circ} \mathrm{C}$ with primary rabbit antibodies (anti-NF- $\kappa \mathrm{B}$ p65 (1:1000), anti- $\beta$-actin (1:1500), anti-H3 (1:800), anti-TLR2 (1:1000), anti-TLR4 (1:1000), or anti-RAGE (1:1000); first three from Cell Signaling Technology (Danvers, MA, USA) and latter three from Abcam, UK). The membranes were then incubated for $1 \mathrm{~h}$ at the room temperature with a goat antirabbit secondary antibody at a dilution of 1:10 000 and the protein bands were detected using an ECL Plus kit (GE Healthcare, Pittsburgh, PA, USA).

\section{RNA Isolation and qRT-PCR}

Total RNA from cells was isolated with Trizol reagent and an RNeasy kit (both from Invitrogen) and reverse transcribed into cDNA with the M-MLV polymerase (Thermo Fisher Scientific, Waltham, MA, USA). qPCR was performed in a 7300 Real-Time PCR System (Applied Biosystems, Warrington, UK) in accordance with the manufacturer's instructions with the following sequence-specific primers: GAPDH, $5^{\prime}$-ATCACTGCCACCCAGAAG-3' and 5'-TCCACGACGGA CACATTG-3'; TLR-2, 5'-CTTCCAGGTCTTCAGTCTTC-3' and $5^{\prime}$-TGATTGCGGACACATCTC-3'; TLR-4, 5'-GCCGTT GGTGTATCTTTG- $3^{\prime}$ and $5^{\prime}$-GCTGTTTGCTCAGGATTC $-3^{\prime}$; and RAGE, 5'-GAAAGCCCTCCTGTCAGCATC-3' and 5'-GGCACCATTCTCTGGCATCTC-3'. All samples were run in triplicate and relative gene expression was determined according to the $2^{-\Delta \Delta \mathrm{Ct}}$ method. The housekeeping gene $G A P D H$ served as the normalization standard.

\section{Statistical Analysis}

Each experiment was conducted independently and repeated at least three times with similar results. The data are reported as mean \pm s.d. The SPSS statistical software version 12.0 (SPSS, Chicago, IL, USA) was used for mean value comparisons of single-factor multiple samples. The homogeneity of variance within the data sets was analyzed with a one-factor analysis of variance (ANOVA) least squares difference test, for parametric data, or a Kruskal-Wallis rank-sum test, for nonparametric data. In all cases, $P$-values $<0.05$ were considered statistically significant.

\section{RESULTS \\ Proliferative Effects of LPS, HMGB1, and LPS Plus HMGB1 on Lung Fibroblasts}

As shown in Figure 1a and b, MTT data demonstrated that, relative to the nonstimulation control, LPS (10, 50, and $100 \mathrm{ng} / \mathrm{ml})$ and HMGB1 $(0.01,0.10$, and $1 \mu \mathrm{g} / \mathrm{ml})$ each had a significant positive effect on cell viability at 12,24 , and $48 \mathrm{~h}$. The effects were both time dependent and dose dependent. Lung fibroblasts treated with both agents $(10 \mathrm{ng} / \mathrm{ml} \mathrm{LPS}$ $+0.01 \mu \mathrm{g} / \mathrm{ml}$ HMGB1, $50 \mathrm{ng} / \mathrm{ml}$ LPS $+0.1 \mu \mathrm{g} / \mathrm{ml} \mathrm{HMGB1}$, and $100 \mathrm{ng} / \mathrm{ml} \mathrm{LPS}+1 \mu \mathrm{g} / \mathrm{ml}$ HMGB1) showed greater induction of cell viability than either LPS- or HMGB1-treated cells (Figure 2a-c). The effects were both time dependent and dose dependent (Figure 2d).

\section{LPS Stimulation Induces Lung Fibroblast Secretion of HMGB1 That Can Be Attenuated by an Anti-HMGB1- Neutralizing Antibody}

As shown in Figure 3, ELISA data demonstrated that stimulation of lung fibroblasts with LPS $(100 \mathrm{ng} / \mathrm{ml})$ for $48 \mathrm{~h}$ resulted in increased levels of HMGB1 in cell culture supernatants, relative to levels in nonstimulated control cells. Pretreatment with an anti-HMGB1-neutralizing antibody $(4 \mu \mathrm{g} / \mathrm{ml})$ for $1 \mathrm{~h}$ attenuated LPS induction of HMGB1 expression, relative to levels observed when cells were pretreated with negative control antibody (chicken anti-mouse IgY). In addition, the MTT assay data showed that LPS $(100 \mathrm{ng} / \mathrm{ml})$ stimulation for $48 \mathrm{~h}$ increased lung fibroblast viability, and that pretreatment with the anti-HMGB1 antibody $(4 \mu \mathrm{g} / \mathrm{ml})$ for $1 \mathrm{~h}$ inhibited the proliferative effect of LPS (Figure 4a-e). 
Table 2 Ten most overrepresented GO terms in each GO category associated with genes responsive to LPS, or HMGB1, or LPS plus HMGB1 stimulation

Class Overrepresented GO terms

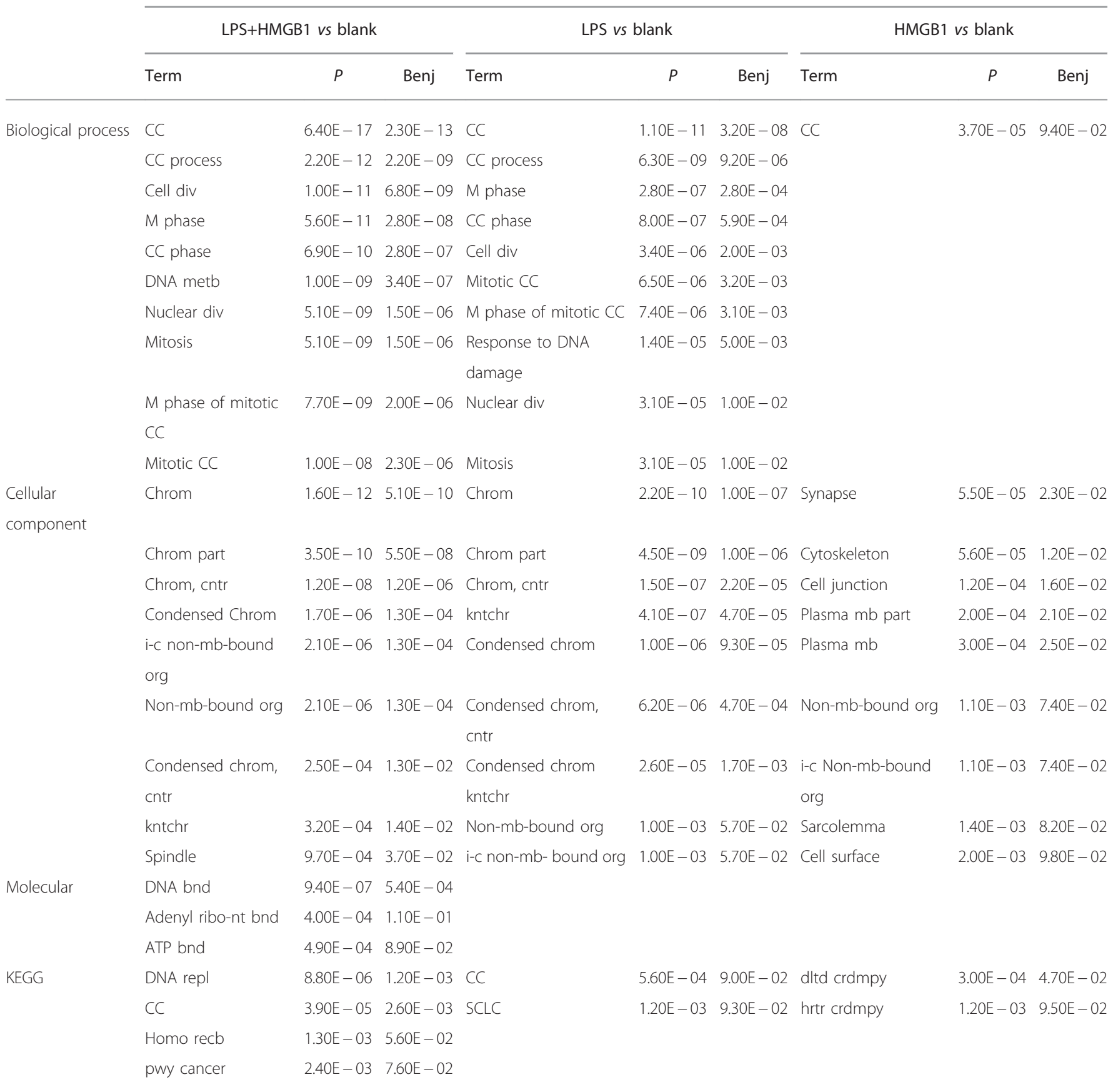

Benj, Benjamini; bnd, binding; CC, cell cycle; chrm, chromosome; cntr, centromeric region; crdmpy, cardiomyopathy; div, division; dltd, dilated; homo recb, homologous recombination; hrtr, hypertrophic; i-c, intracellular; kntchr, kinetochore; mb, membrane; metb, metabolic process; nt, nucleotide; org, organelle; pwy, pathways in; repl, replication; SCLC, small-cell lung cancer.

The NF-kB Pathway Implicated in Proproliferative Effects of HMGB1 and LPS

The DNA microarray analysis results profiling differentially expressed genes (cutoff value of $>1.2$ fold change) after stimulation with LPS (100 ng/ml), HMGB1 $(1 \mu \mathrm{g} / \mathrm{ml})$, or both (100 ng/ml LPS plus $1 \mu \mathrm{g} / \mathrm{ml}$ HMGB1) are reported in Tables 1 and 2 . We found that 2231, 1707, and 860 genes were upregulated relative to control levels in the LPS, HMGB1, and 
Table 3 Up- and down-regulated genes in LPS- and/or HMGB1-treated lung fibroblasts

\begin{tabular}{|c|c|c|c|c|c|}
\hline & LPS vs Con. & HMGB1 vs Con. & LPS+HMGB1 vs Con. & LPS+HMGB1 vs LPS & LPS+HMGB1 vs HMGB1 \\
\hline \multirow[t]{8}{*}{ Upregulated genes } & LOC100042970 & B130049M08Rik & 2610101N10Rik & Pim2 & Pnmt \\
\hline & $5430420 C 16 R i k$ & LOC331177 & A530095A18Rik & $B C 19$ & 4933407P14Rik \\
\hline & LOC100039693 & Rnps1 & Csf3 & Ptgs 1 & Slc2a9 \\
\hline & Tob2 & $\operatorname{Atg} 4 \mathrm{C}$ & LOC100042970 & Zbtb33 & Arhgap6 \\
\hline & D930020N02Rik & Dsgib & Spin & Flg2 & Olfrn143 \\
\hline & KIh/4 & Olfr1031 & B4galnt3 & col11a2 & $\operatorname{Tm} 4 s f 20$ \\
\hline & Glce & C130023l09Rik & Setd8 & LOC100044736 & Dsg1b \\
\hline & Krtap5-4 & 4732426B21Rik & Vrk1 & 2210409F01Rik & BC050777 \\
\hline \multirow{7}{*}{ Downregulated genes } & Aoah & Usel & $5 / c 2 a 9$ & Slc37a4 & Art5 \\
\hline & Sspo & Jph2 & Matn1 & $K / h / 4$ & Pim2 \\
\hline & Atp1b1 & Glrx3 & 41523 & D930014E17Rik & Gsta2 \\
\hline & Bmp5 & Slc16a6 & Olfm 1 & LOC385707 & LOC669458 \\
\hline & Ptgs 1 & Sspo & Sfmbt2 & Oas3 & Lsm14b \\
\hline & 1700016D06Rik & Mep1b & 1700081D17Rik & Tdrd1 & D930008012Rik \\
\hline & LOC435565 & Tnip2 & Fgf1 & Slc2a9 & 6330548G22Rik \\
\hline
\end{tabular}

LPS+HMGB1 groups, respectively. In addition, 764, 580, and 740 genes, respectively, were downregulated relative to controls in these groups. We then verified some of the results using qRT-PCR (data not shown). The most significantly upand down-regulated genes after LPS plus HMGB1 treatment are shown in Table 3. Interestingly, as shown in Figure 5, a number of genes encoding proteins related to a variety of signaling pathways or cell proliferation and growth (according to KEGG pathway analysis) were upregulated in the LPS + HMGB1-stimulated cells, including constituents of the NF$\kappa \mathrm{B}$ signaling pathway and of the transforming growth factor- $\beta$ (TGF- $\beta$ ) and phosphatidyl inositol 3-kinase (PI3K)-Akt signaling pathways.

We further confirmed the role of the $\mathrm{NF}-\kappa \mathrm{B}$ signaling pathway in mediation of LPS, HMGB1, or LPS+HMGB1stimulated cell proliferation (Figure 6a-e). The data showed that the NF- $\kappa \mathrm{B}$ signaling pathway had an additive effect on HMGB1- and/or LPS-induced lung fibroblast proliferation. To further verify posttreatment activation of the $\mathrm{NF}-\kappa \mathrm{B}$ pathway, we assessed cytosolic and nuclear levels of the NF- $\kappa \mathrm{B}$ p65 protein (Figure $6 f$ and g). Both LPS and HMGB1 decreased cytosolic levels of NF- $\kappa \mathrm{B}$ p 65 , and increased nuclear levels, suggesting that the treatments promoted translocation of $\mathrm{NF}-\kappa \mathrm{B}$ p 65 to the nucleus. Furthermore, application of an HMGB1-neutralizing antibody attenuated LPS-induced nuclear NF- $\kappa \mathrm{B}$ p65 levels $(P<0.05)$, indicating that HMGB1 was involved in LPS-induced NF- $\kappa \mathrm{B}$ activation.

\section{LPS- and/or HMGB1-Stimulated Secretion of MMP-2, MMP-9, and TIMP-2 in Lung Fibroblasts}

Examination of cellular supernatant levels of MMP-2, MMP-9, and TIMP-2 revealed that, compared with the control group, the LPS and HMGB1 treatments each stimulated secretion of these proteins (all $P<0.05$ ). The combined LPS+HMGB1 treatment elevated MMP-2, MMP-9, and TIMP-2 levels significantly more than the LPS-alone treatment (all $P<0.05$ ). Meanwhile, the HMGB1-neutralizing antibody inhibited LPS-induced secretion of MMP-2, MMP-9, and TIMP-2, indicating that HMGB1 was involved in the LPS-mediated induction of the secretion of these molecules (Figure $7 \mathrm{a}-\mathrm{c}$ ).

\section{NF-KB Pathway Mediated LPS- and HMGB1-Stimulated Secretion of MMP-2, MMP-9, and TIMP-2 in Lung Fibroblasts}

Cytosolic NF- $\kappa$ B p65 protein levels were significantly higher in cells treated with the NF- $\kappa \mathrm{B}$ inhibitor PDTC $(30 \mu \mathrm{M})$ only and in cells treated with LPS+HMGB1 (100 ng/ml LPS and $1 \mu \mathrm{g} / \mathrm{ml}$ HMGB1) and PDTC than in the LPS+HMGB1 group not exposed to PDTC $(P<0.05)$, whereas nuclear NF- $\kappa \mathrm{B}$ p65 


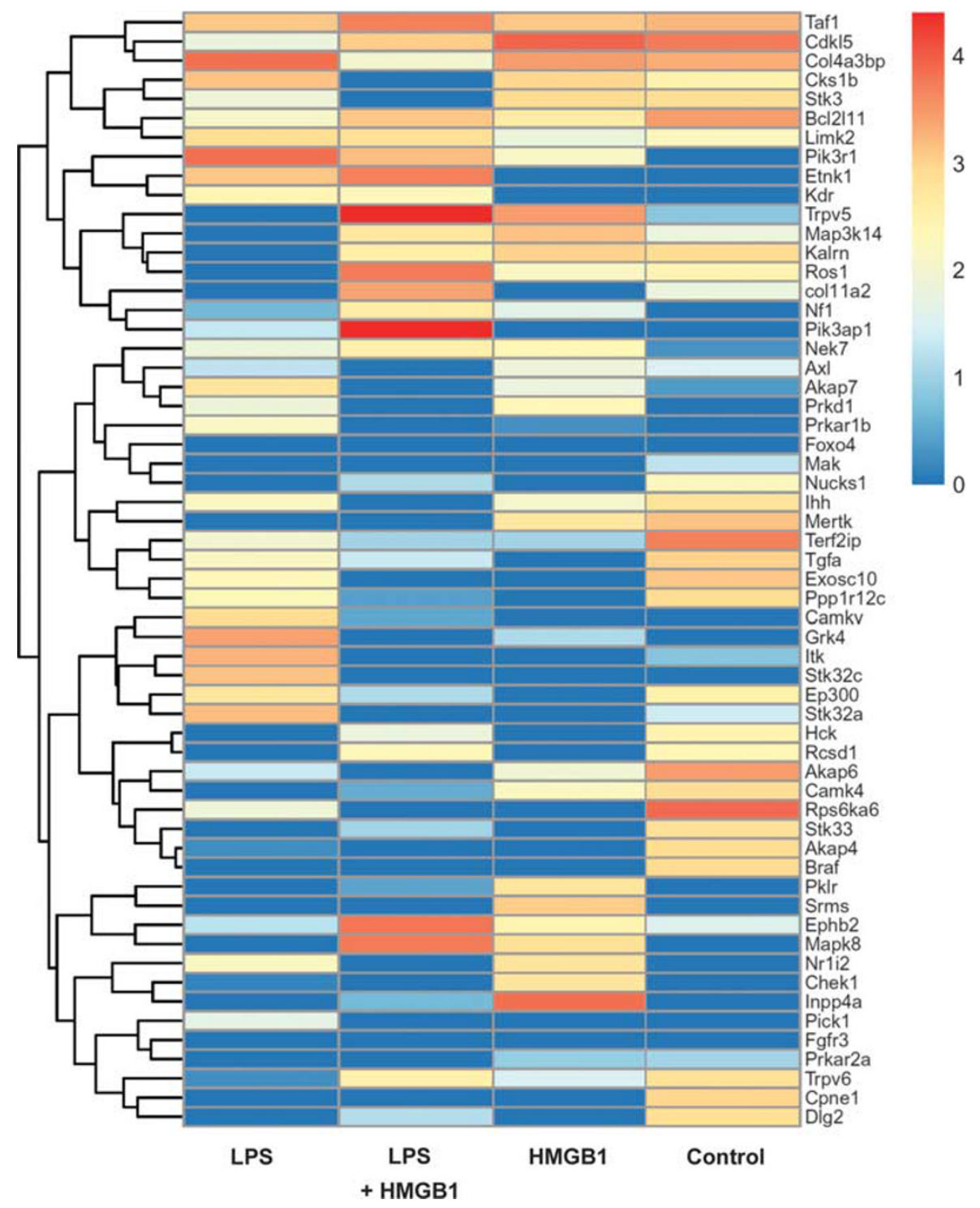

Figure 5 Heat map representation of candidate genes identified as being involving in lung fibroblast proliferation. From left to right: lane 1 is LPStreated cells, lane 2 is LPS+HMGB1-treated cells, lane 3 is HMGB1-treated cells, and lane 4 is untreated controls. Red nodes represent the key regulatory genes involved in LPS- and/or HMGB1-stimulated fibroblast proliferation. Similarities are indicated with matching node color.

protein levels were significantly lower in the PDTC-exposed groups $(P<0.05 v s$ LPS+HMGB1; Figure 7d and e). MMP-2, MMP-9, and TIMP-1 levels were significantly increased in cells treated with LPS+HMGB1, but significantly decreased after PDTC exposure (all $P<0.05$ vs LPS+HMGB1; Figure $7 \mathrm{f}-$ $h$ ), pointing to the NF- $\kappa$ B pathway as a potential mediator of LPS and HMGB1 effects on secretion of MMP-2, MMP-9, and TIMP-1.

\section{LPS and/or HMGB1 Upregulated Expression of TLR4, TLR2, and RAGE in Lung Fibroblasts}

The relative levels of Tlr2, Rage, and, especially, Tlr4 mRNA were upregulated after LPS treatment (all $P<0.05 v s$ untreated controls) and further upregulated by the LPS+HMGB1 treatment (all $P<0.05$ vs LPS+HMGB1). The HMGB1neutralizing antibody attenuated these increases $(P<0.05$; Figure $8 \mathrm{a})$. The western blot data were consistent with the qRT-PCR data (Figure $8 \mathrm{~b}$ ).

\section{TLR4-Mediated LPS- and HMGB1-Induced Activation of NF-KB Signaling}

Pretreating cells with anti-TLR4 antibody before LPS + HMGB1 treatment inhibited LPS- and HMGB-stimulated NF- $\mathrm{KB}$ activation in lung fibroblasts $(P<0.05$; Figure $8 \mathrm{c}$ and d). Pretreatments with anti-TLR2 antibody or RAGE-Fc did not produce as robust inhibition as that observed with the anti-TLR4 antibody pretreatment, suggesting that LPS- and 
a

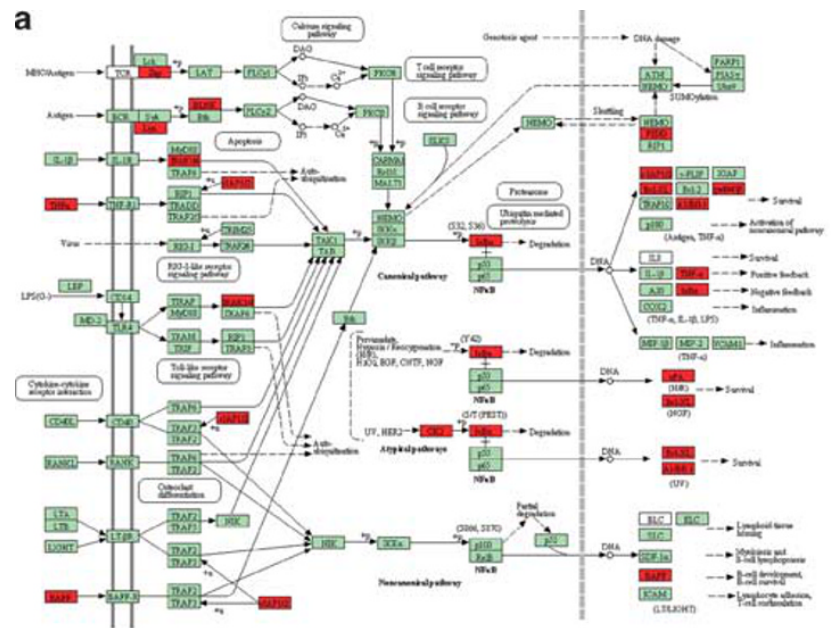

LPS vs. Control

C

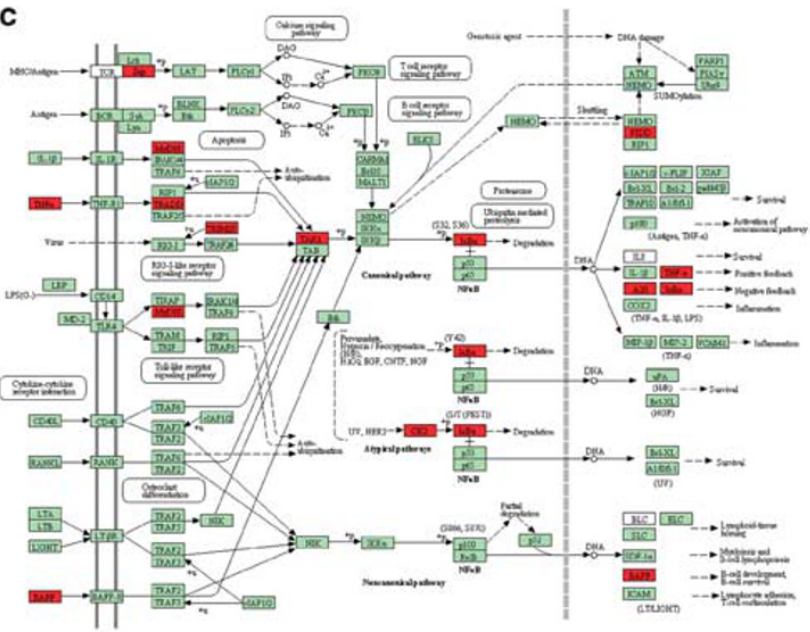

LPS + HMGB1 vs. Control b

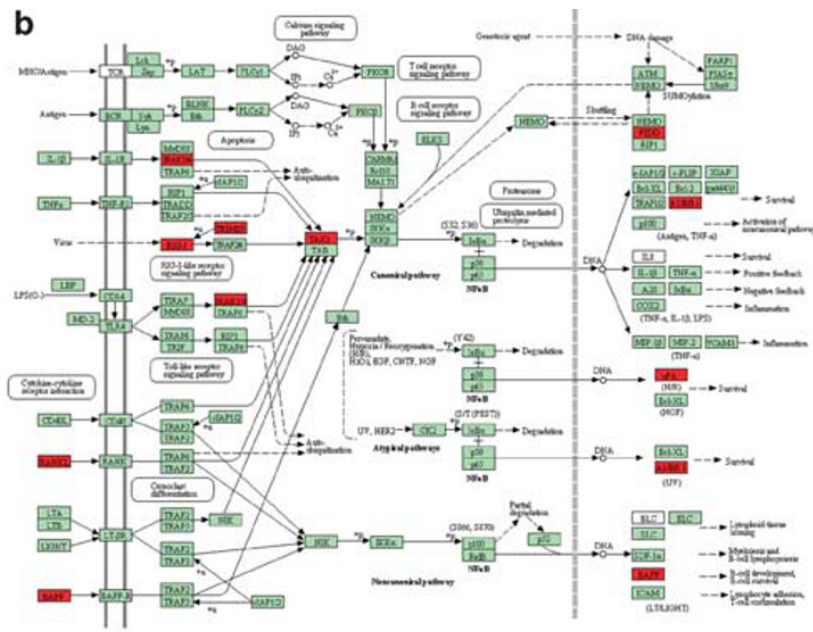

HMGB1 vs. Control

d

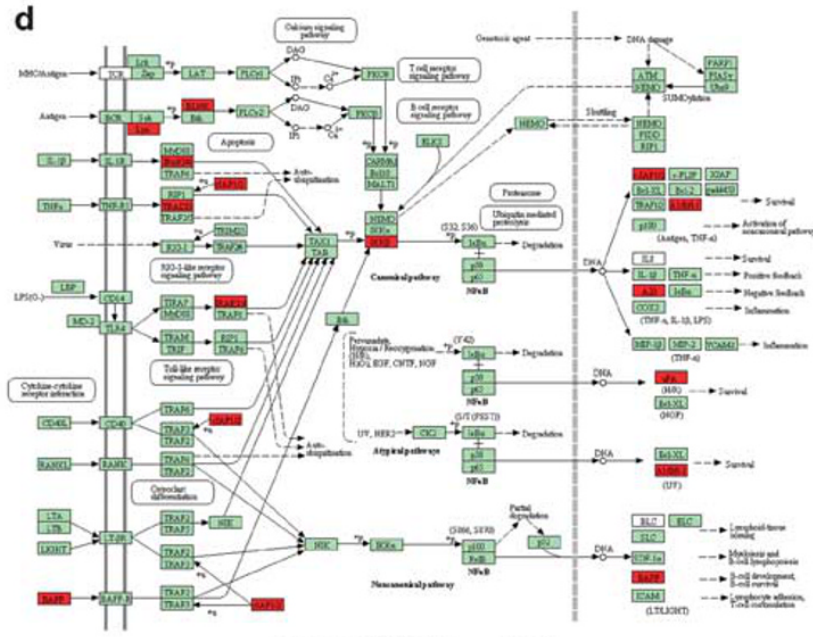

LPS + HMGB1 vs. LPS

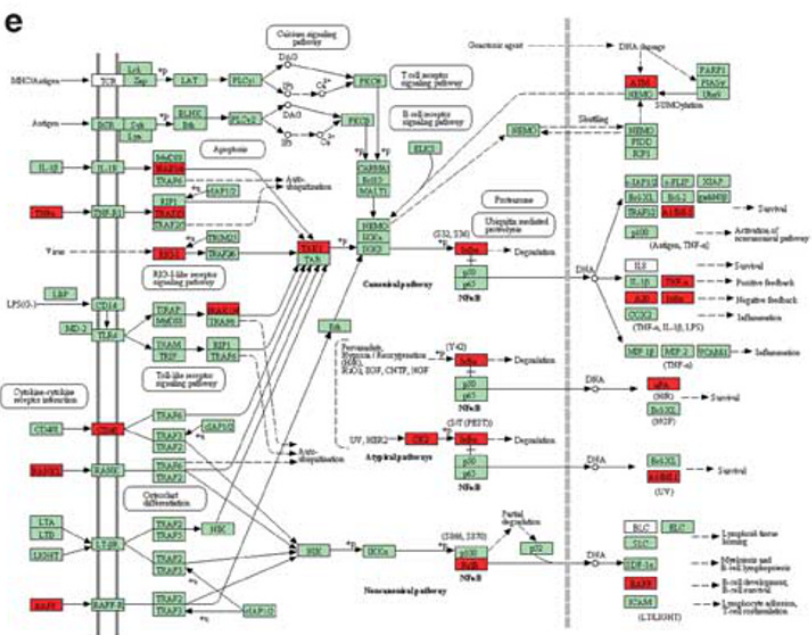

LPS + HMGB1 vs. HMGB1

Figure 6 NF-KB pathway regulation of HMGB1 and LPS effects on lung fibroblasts. DNA microarray and KEGG pathway enrichment analysis of lung fibroblasts treated for $24 \mathrm{~h}$ with LPS alone $(100 \mathrm{ng} / \mathrm{ml})$, HMGB1 alone $(1 \mu \mathrm{g} / \mathrm{ml})$, or both $(100 \mathrm{ng} / \mathrm{ml}$ LPS and $1 \mu \mathrm{g} / \mathrm{ml}$ HMGB1) indicated that the treatments stimulated intracellular signal transduction pathways. (a-e) Differentially expressed NF- $\kappa$ B pathway-related genes in lung fibroblasts following each treatment. Green color indicates no change, and red color indicates upregulation compared with control cells. (f) Cytosolic NF- $\kappa B$ p65 protein levels following LPS alone, HMGB1 alone, or a combination of both treatments in lung fibroblasts. (g) Nuclear NF-KB p65 protein levels following LPS alone, HMGB1 alone, or a combination of both treatments in lung fibroblasts. ${ }^{*} P<0.05$ vs controls. ${ }^{\dagger} P<0.05$ vs LPS-alone group. 


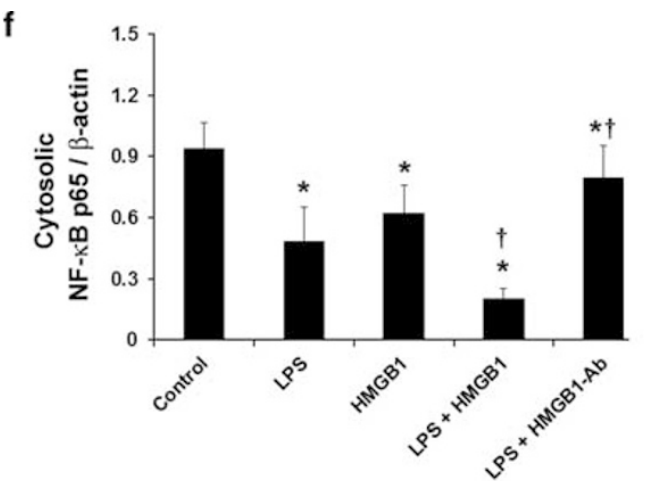

g
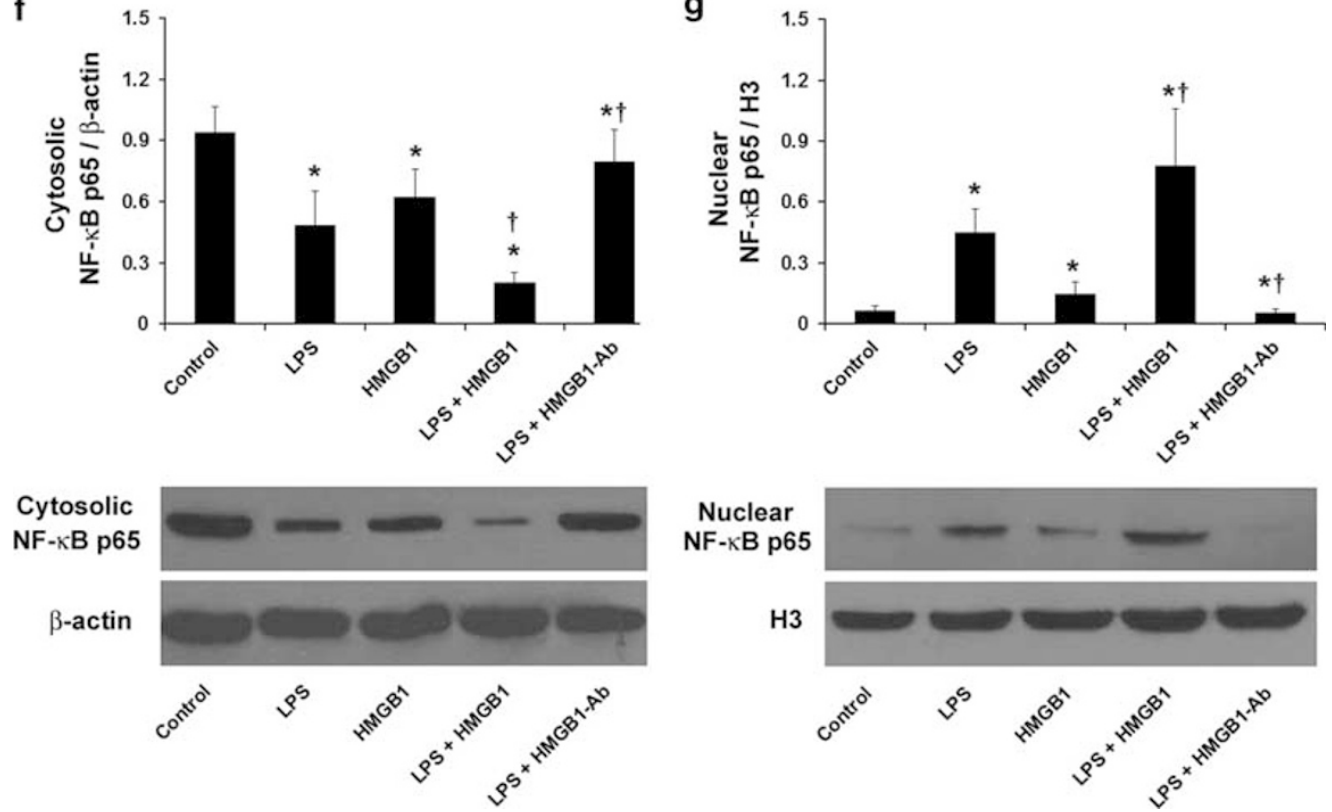

Figure 6 Continued.

HMGB1-induced activation of the NF- $\kappa$ B signaling pathway is mediated through the TLR4.

\section{DISCUSSION}

Our current study demonstrated that LPS and HMGB1, individually or in combination, were able to induce lung fibroblast proliferation in a dose- and time-dependent manner, and that HMGB1 treatment results in cell proliferation that exceeds that seen with LPS. This study also showed, for the first time, that LPS can induce lung fibroblasts to secrete HMGB1 secretion in vitro. In addition, the DNA microarray data showed that fibroblasts stimulated with LPS, HMGB1, or LPS+HMGB1 exhibited pronounced changes in the expression of genes encoding proteins in the NF- $\kappa \mathrm{B}$, TGF$\beta$, and PI3K-Akt signaling pathways. The same three treatments were able to induce TLR4 expression, and antiTLR4 antibody blocked the activating effects of LPS+HMGB1 on NF- $\kappa \mathrm{B}$ signaling. The present results suggest that targeting these pathways, especially TLR4/NF- $\kappa \mathrm{B}$, could potentially attenuate pulmonary fibrosis.

Our results related to LPS- and HMGB1-induced lung fibroblast proliferation are consistent with several previous studies. ${ }^{3,5,28}$ Our finding that HMGB1 can enhance LPSinduced lung fibroblast proliferation is novel, yet consistent with findings of cooperative effects in other types of cells, including synovial fibroblasts, macrophages, and human monocytes. ${ }^{29-31}$ For example, Wahamaa et al ${ }^{32}$ showed that HMGB1 increased LPS-induced secretion of cytokines, such as tumor necrosis factor- $\alpha$ (TNF- $\alpha$ ), interleukin (IL)-6, and IL-8, in synovial fibroblasts. HMGB1 was also shown to enhance the proinflammatory activity of LPS in activated macrophages by promoting the phosphorylation of $\mathrm{p} 38$ mitogen-activated protein kinase. ${ }^{29}$ In addition HMGB1 binding to LPS has been reported to facilitate LPS cellular transformation to a CD14+ profile that enhances LPSmediated TNF- $\alpha$ production in human monocytes. ${ }^{30}$ The present study fits with these prior data, and also provides new clues about the mechanisms involved, as described below.

LPS has been reported previously to induce endogenous HMGB1 secretion, directly or indirectly, from various cell types (macrophages, myocardial fibroblasts, and gingival fibroblasts). ${ }^{20,31,33}$ Our data showed, for the first time, that LPS was able to induce lung fibroblasts to secrete HMGB1 and that anti-HMGB1-neutralizing antibody blocked the effects of LPS on lung fibroblast proliferation, suggesting that LPS effects on lung fibroblast proliferation are mediated, at least in large part, through HMGB1. Furthermore, these results indicate that endogenous HMGB1 can collude with LPS in stimulating lung fibroblast proliferation and thereby may function to exacerbate pulmonary fibrosis.

Mechanistically, we found that HMGB1 stimulation produces strong changes in the expression of NF- $\kappa \mathrm{B}$ signal transduction pathway components and nuclear translocation of NF- $\kappa \mathrm{B}$ p65. These data are consistent with the findings of Wu et $a^{31}$ showing that LPS can induce HMGB1 relocation and release through activation of the NF- $\kappa \mathrm{B}$ signal transduction pathway in murine macrophage-like RAW264.7 cells. The NF- $\kappa \mathrm{B}$ signaling was important in HMGB1-induced synovial fibroblast migration and the release of inflammatory mediators $^{34}$ and associated with abnormal proliferation of lung or cardiac fibroblasts. ${ }^{35,36}$ However, before this study, there was no direct evidence demonstrating whether activation of the NF- $\kappa \mathrm{B}$ signaling was involved in LPS-induced secretion of endogenous HMGB1 from lung fibroblasts or 

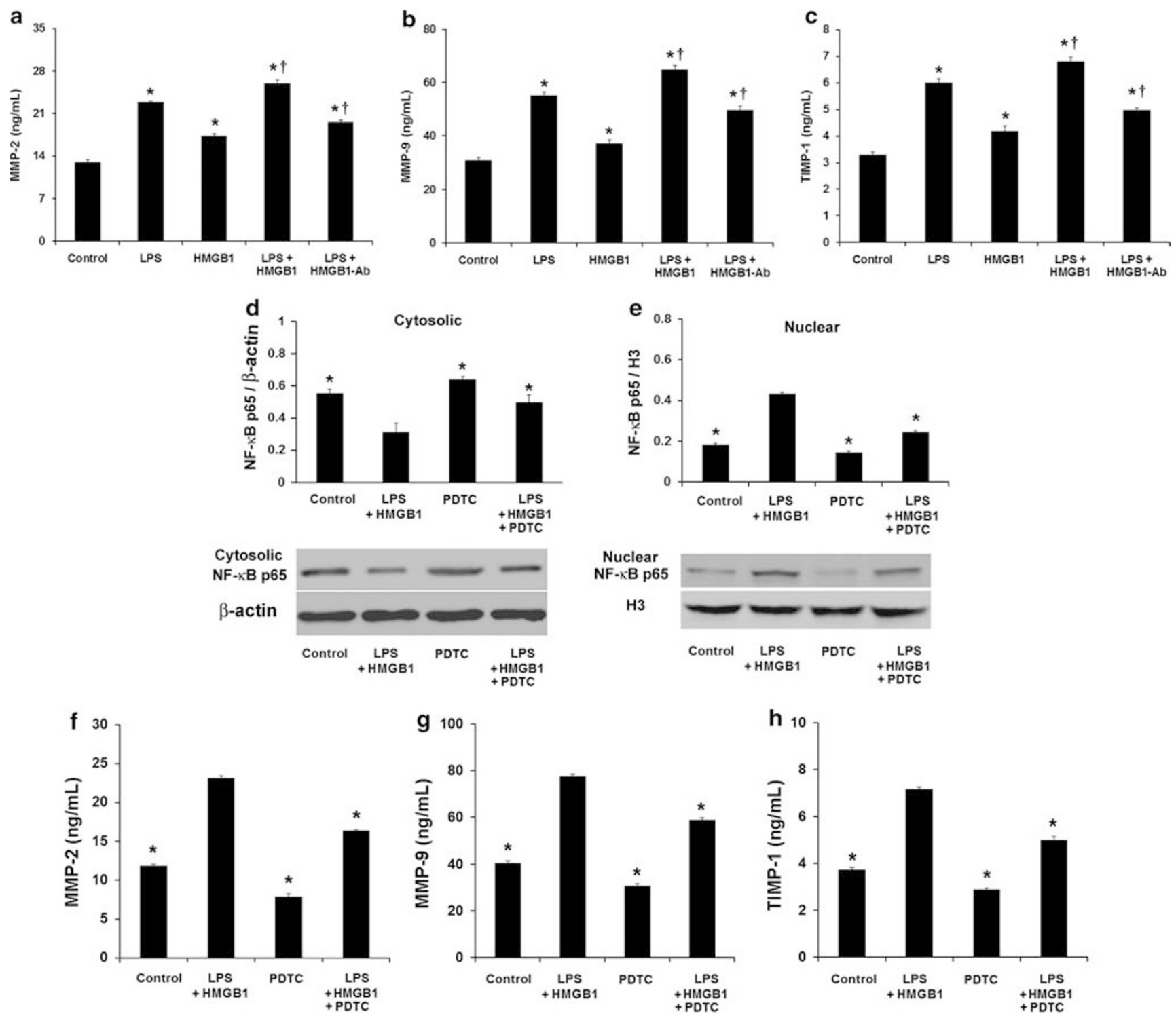

Figure 7 NF- $K B$ pathway involvement in LPS- and HMGB1-mediated induction of MMP-2, MMP-9, and TIMP-2 secretion. (a-c) Supernatant levels of MMP-2, MMP-9, and TIMP-2 proteins after 48-h LPS and/or HMGB1 treatment of lung fibroblasts with or without a 30-min anti-HMGB1 antibody pretreatment. Mean values from triplicate ELISA experiments are shown with s.d. error bars. ${ }^{*} P<0.05$ vs controls. ${ }^{\dagger} P<0.05$ vs LPS-alone group. (d and e) Cytosolic and nuclear NF-KB p65 protein levels, assessed by western blot, of lung fibroblasts treated for $48 \mathrm{~h}$ with LPS and HMGB1 with or without a $30-$ min pretreatment with the NF-KB inhibitor PDTC. The fold changes from triplicate experiments are shown with s.d. error bars. ${ }^{*} P<0.05$ vs LPS+HMGB1 group. (f-h) Supernatant levels of MMP-2, MMP-9, and TIMP-2 proteins, as determined by ELISAs, for the same treatment groups as in (d) and (e). Mean values from triplicate ELISA experiments are shown with s.d. error bars. ${ }^{*} P<0.05$ vs LPS+HMGB1 group.

that NF- $\kappa \mathrm{B}$ signaling was crucial for LPS- and/or HMGB1induced lung fibroblast proliferation. The presently observed changes in expression of the NF- $\kappa \mathrm{B}$ pathway constituents in LPS-, HMGB1-, and LPS+HMGB1-stimulated cells suggest that abnormal activation of the NF- $\kappa \mathrm{B}$ pathway may play a role in LPS-induced secretion of endogenous HMGB1 and lung fibroblast proliferation. Furthermore, the TLR4 protein, whose expression was also regulated by these treatments, has been associated previously with the development and progression of pulmonary fibrosis. ${ }^{37,38}$ The presently observed changes in MMP-2, MMP-9, and TIMP-2 further confirm the importance of the NF- $\kappa \mathrm{B}$ pathway in mediating the effects of LPS and HMGB1 on lung fibroblast proliferation.

In conclusion, the current study demonstrated that LPS and HMGB1, individually or in combination, induce lung fibroblast proliferation and provided insights into the molecular events underlying these effects. Our in vitro fibroblast proliferation findings should be confirmed in in vivo lung fibrosis studies. In particular, the importance of 
a

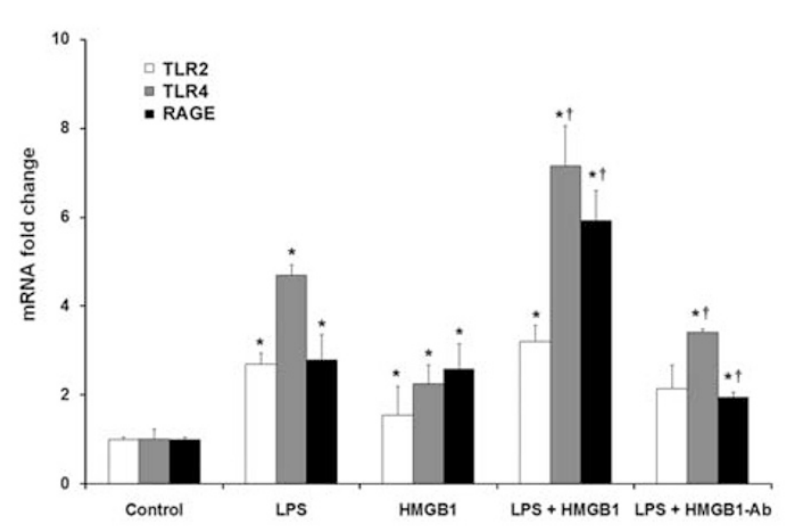

C
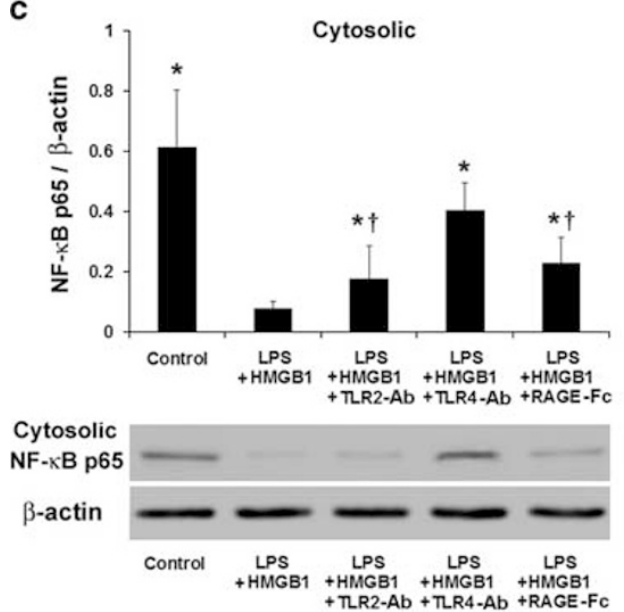

b

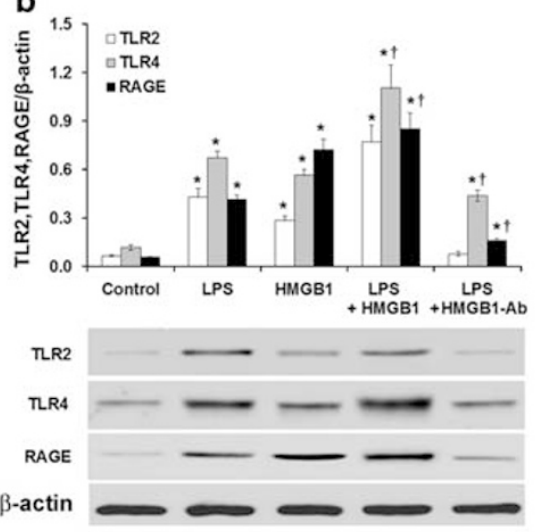

d
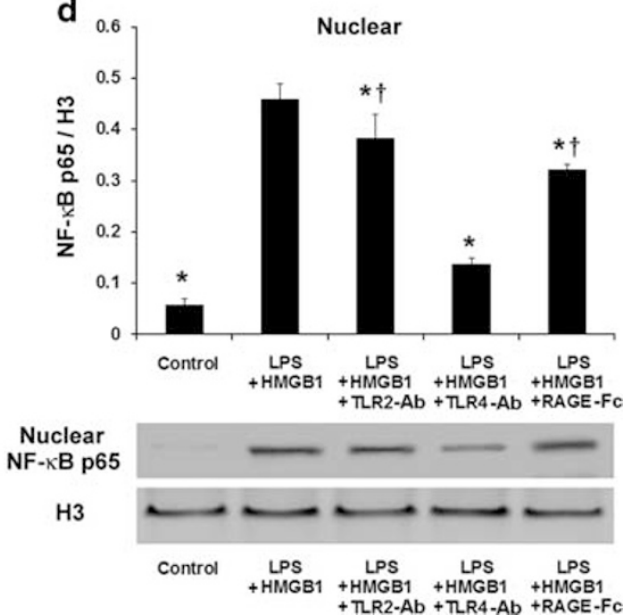

Figure 8 LPS and/or HMGB1 treatment-mediated expression of TLR2, TLR4, and RAGE and activation of NF-KB. (a and b) Levels of TLR2, TLR4, and RAGE mRNAs and proteins, assessed by qRT-PCR and western blots, respectively, after 48-h LPS and/or HMGB1 treatment of lung fibroblasts with or without a 1-h anti-HMGB1 antibody pretreatment. Fold change values from triplicate experiments are shown with s.d. error bars. ${ }^{*} P<0.05$ vs controls. ${ }^{\dagger} P<0.05$ vs LPS-alone group. (c and d) Cytosolic and nuclear NF-KB p65 protein levels, as assayed by western blot, following 1-h pretreatment with TLR2, TLR4, and RAGE antibody treatments and 48-h LPS and HMGB1 stimulation. Fold changes from triplicate experiments are shown with s.d. error bars. ${ }^{*} P<0.05$ vs LPS+HMGB1 group. ${ }^{\dagger} P<0.05$ vs LPS+HMGB1+TLR4-Ab group.

the proteins implicated in the regulation of fibroblast proliferation/fibrosis in this study should be examined further.

\section{ACKNOWLEDGMENTS}

This research was supported by grants from the National Natural Science Foundation of China (NSFC, No. 81270122, 81170062). The funders had no role in study design, data collection and analysis, the decision to publish, or preparation of the manuscript.

\section{DISCLOSURE/CONFLICT OF INTEREST}

The authors declare no conflict of interest.

1. Binder $\mathrm{H}$, Schumacher $\mathrm{M}$. Comment on 'Network-constrained regularization and variable selection for analysis of genomic data'. Bioinformatics 2008;24:2566-2568.

2. Li H, Du S, Yang L et al. Rapid pulmonary fibrosis induced by acute lung injury via a lipopolysaccharide three-hit regimen. Innate Immun 2009;15:143-154.

3. He Z, Zhu Y, Jiang H. Toll-like receptor 4 mediates lipopolysaccharideinduced collagen secretion by phosphoinositide3-kinase-Akt pathway in fibroblasts during acute lung injury. J Recept Signal Transduct Res 2009;29:119-125.

4. He Z, Gao Y, Deng $\mathrm{Y}$ et al. Lipopolysaccharide induces lung fibroblast proliferation through Toll-like receptor 4 signaling and the phosphoinositide3-kinase-Akt pathway. PLoS One 2012;7:e35926.

5. He Z, Wang $X$, Deng $Y$ et al. Epigenetic regulation of Thy-1 gene expression by histone modification is involved in lipopolysaccharideinduced lung fibroblast proliferation. J Cell Mol Med 2013;17:160-167.

6. He Z, Deng Y, Li W et al. Overexpression of PTEN suppresses lipopolysaccharide-induced lung fibroblast proliferation, differentiation and collagen secretion through inhibition of the PI3-K-AktGSK3beta pathway. Cell Biosci 2014;4:2.

7. Andersson $\mathrm{U}$, Tracey KJ. HMGB1 is a therapeutic target for sterile inflammation and infection. Annu Rev Immunol 2011;29:139-162.

8. Erlandsson Harris $\mathrm{H}$, Andersson U. Mini-review: The nuclear protein HMGB1 as a proinflammatory mediator. Eur J Immunol 2004;34: 1503-1512.

9. Muller S, Scaffidi P, Degryse B et al. New EMBO members' review: the double life of HMGB1 chromatin protein: architectural factor and extracellular signal. EMBO J 2001;20:4337-4340.

10. Stros M. HMGB proteins: interactions with DNA and chromatin. Biochim Biophys Acta 2010;1799:101-113.

11. Yanai H, Ban T, Taniguchi T. Essential role of high-mobility group box proteins in nucleic acid-mediated innate immune responses. J Intern Med 2011;270:301-308. 
12. Yang $\mathrm{H}$, Antoine $\mathrm{DJ}$, Andersson $\mathrm{U}$ et al. The many faces of HMGB1: molecular structure-functional activity in inflammation, apoptosis, and chemotaxis. J Leukoc Biol 2013;93:865-873.

13. Deng $Y$, Yang Z, Gao $Y$ et al. Toll-like receptor 4 mediates acute lung injury induced by high mobility group box-1. PLoS One 2013;8:e64375.

14. Yang Z, Deng Y, Su D et al. TLR4 as receptor for HMGB1-mediated acute lung injury after liver ischemia/reperfusion injury. Lab Invest 2013;93:792-800

15. Hamada N, Maeyama T, Kawaguchi $T$ et al. The role of high mobility group box1 in pulmonary fibrosis. Am J Respir Cell Mol Biol 2008;39: 440-447.

16. Ulloa L, Messmer D. High-mobility group box 1 (HMGB1) protein: friend and foe. Cytokine Growth Factor Rev 2006;17:189-201.

17. Hreggvidsdottir HS, Ostberg $\mathrm{T}$, Wahamaa $\mathrm{H}$ et al. The alarmin HMGB1 acts in synergy with endogenous and exogenous danger signals to promote inflammation. J Leukoc Biol 2009;86:655-662.

18. Chitanuwat A, Laosrisin N, Dhanesuan N. Role of HMGB1 in proliferation and migration of human gingival and periodontal ligament fibroblasts. J Oral Sci 2013;55:45-50.

19. Sun NK, Chao CC. The cytokine activity of HMGB1-extracellular escape of the nuclear protein. Chang Gung Med J 2005;28:673-682.

20. Feghali K, Iwasaki K, Tanaka $\mathrm{K}$ et al. Human gingival fibroblasts release high-mobility group box-1 protein through active and passive pathways. Oral Microbiol Immunol 2009;24:292-298.

21. Yang ZW, Deng YX, Su DS et al. TLR4 as receptor for HMGB1-mediated acute lung injury after liver ischemia/reperfusion injury. Lab Invest 2013:93:792-800.

22. Gene Ontology Consortium. The Gene Ontology (GO) project in 2006 Nucleic Acids Res 2006;34:D322-D326.

23. Ashburner $M$, Ball $C A, B$ lake JA et al. Gene ontology: tool for the unification of biology. The Gene Ontology Consortium. Nat Genet 2000;25:25-29.

24. Dupuy D, Bertin N, Hidalgo CA et al. Genome-scale analysis of in vivo spatiotemporal promoter activity in Caenorhabditis elegans. Nat Biotechnol 2007;25:663-668.

25. Kanehisa M, Goto S, Kawashima $S$ et al. The KEGG resource for deciphering the genome. Nucleic Acids Res 2004;32:D277-D280.

26. Yi M, Horton JD, Cohen JC et al. WholePathwayScope: a comprehensive pathway-based analysis tool for highthroughput data. BMC Bioinformatics 2006;7:30.

27. Draghici S, Khatri $\mathrm{P}$, Tarca AL et al. A systems biology approach for pathway level analysis. Genome Res 2007:17:1537-1545.
28. He $Z$, Zhu $Y$, Jiang $H$. Inhibiting toll-like receptor 4 signaling ameliorates pulmonary fibrosis during acute lung injury induced by lipopolysaccharide: an experimental study. Respir Res. 2009;10:126

29. Qin YH, Dai SM, Tang GS et al. HMGB1 enhances the proinflammatory activity of lipopolysaccharide by promoting the phosphorylation of MAPK p38 through receptor for advanced glycation end products. $\mathrm{J}$ Immunol 2009;183:6244-6250.

30. Youn JH, Oh YJ, Kim ES et al. High mobility group box 1 protein binding to lipopolysaccharide facilitates transfer of lipopolysaccharide to CD14 and enhances lipopolysaccharide-mediated TNF-alpha production in human monocytes. J Immunol. 2008;180:5067-5074.

31. Wu CX, Sun $H$, Liu $Q$ et al. LPS induces HMGB1 relocation and release by activating the NF-kappaB-CBP signal transduction pathway in the murine macrophage-like cell line RAW264.7. J Surg Res 2012;175: 88-100.

32. Wahamaa $\mathrm{H}$, Schierbeck $\mathrm{H}$, Hreggvidsdottir $\mathrm{HS}$ et al. High mobility group box protein 1 in complex with lipopolysaccharide or ILpromotes an increased inflammatory phenotype in synovial fibroblasts. Arthritis Res Ther 2011;13:R136.

33. $\mathrm{Xu} \mathrm{H}, \mathrm{Su} \mathrm{Z}, \mathrm{Wu} J$ et al. The alarmin cytokine, high mobility group box 1 , is produced by viable cardiomyocytes and mediates the lipopolysaccharide-induced myocardial dysfunction via a TLR4/phosphatidylinositol 3-kinase gamma pathway. J Immunol 2010;184: 1492-1498.

34. Hou CH, Fong YC, Tang CH. HMGB-1 induces IL- 6 production in human synovial fibroblasts through c-Src, Akt and NF-kappaB pathways. J Cell Physiol 2011;226:2006-2015.

35. Seidel P, Merfort I, Tamm M et al. Inhibition of NF-kappaB and AP-1 by dimethylfumarate correlates with down-regulated IL-6 secretion and proliferation in human lung fibroblasts. Swiss Med Wkly 2010;140: w13132.

36. Chen HN, Wang DJ, Ren MY et al. TWEAK/Fn14 promotes the proliferation and collagen synthesis of rat cardiac fibroblasts via the NF-small ka, CyrillicB pathway. Mol Biol Rep 2012;39:8231-8241.

37. Chitra P, Saiprasad G, Manikandan R et al. Berberine attenuates bleomycin induced pulmonary toxicity and fibrosis via suppressing NFkappaB dependant TGF-beta activation: a biphasic experimental study Toxicol Lett 2013;219:178-193.

38. Krug LT, Torres-Gonzalez E, Qin Q et al. Inhibition of NF-kappaB signaling reduces virus load and gammaherpesvirus-induced pulmonary fibrosis. Am J Pathol 2010;177:608-621. 